\title{
Healing in a Hospital; Scientific Evidence that Spiritual Healing Improves Health
}

\author{
Sandy Edwards* \\ Member of The Healing Trust, UK \\ *Corresponding author: Sandy Edwards, Member of The Healing Trust, UK
}

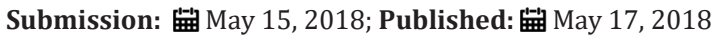

\section{Opinion}

Despite no sign of a natural healing ability, I trained to be a spiritual healer with The Healing Trust, a non-religious UK charity. Ten years later, I instigated probably the largest medical research trial of healing in the world.

Patients with long term illness put an ongoing strain on medical resources. Our research trial aimed to establish whether adding spiritual healing to conventional care would help patients suffering with irritable bowel syndrome (IBS) and inflammatory bowel disease (IBD). The trial was led by the University of Birmingham, a Russell Group university known for first-rate research. The methodology was approved by a team of scientists appointed by the National Lottery, which provided full funding $(£ 205,000)$.

IBS affects over $10 \%$ of the population. IBD affects over $0.5 \%$ of the population. There is no medical cure for either condition and conventional treatments are often ineffective. Every aspect of a patient's life is affected by IBS or IBD symptoms. The symptoms are highly embarrassing, unpredictable, painful and debilitating.

Dr Sukhdev Singh, consultant physician at Good Hope Hospital, Birmingham, allowed me to work as a volunteer spiritual healer in his clinic. I gave his gastroenterology outpatients a single 20-minute session of spiritual healing after their consultation with him. In those first months, he would see each patient again, directly after their healing session, and he was intrigued by what he saw. Although these patients were sceptical that healing could help them, they reported a range of positive responses, some of which were dramatic and long-lasting.

I created a questionnaire and conducted an audit of patient responses:

A. http://www.thehealingtrust.org.uk/research/hospitalaudit-of-75-patients

B. http://www.thehealingtrust.org.uk/research/hospitalaudit-of-192-patients

Results revealed significant improvements regarding pain, anxiety, vitality, sleep quality and relationships. Patients continued

to benefit one week after the healing session and possibly longer but this was the extent of my study.

A few weeks after starting my audit, the National Lottery announced their offer of research funding. They had never offered research funding before, and said they never would again. Dr Singh brought together the necessary parties to apply. Against strong competition, we were successful and gained full funding for our two-year study.

The main points are:

A. Funded by the National Lottery $(£ 205,000)$

B. The application for funding was supported by a hospital audit of gastroenterology outpatients http://www. thehealingtrust.org.uk/research/hospital-audit-of-75patients/

C. The trial was led by the University of Birmingham, a Russell Group university known for first-rate research

D. The methodology was approved by a team of scientists appointed by the Lottery

E. With 200 patients, each receiving five healing sessions, this is probably the largest controlled clinical research trial of healing in the world.

F. The two-year study involved 200 NHS hospital patients with longstanding illnesses:

a. Irritable bowel syndrome (IBS), which affects over $10 \%$ of the population

b. Inflammatory bowel disease (IBD), which affects over $0.5 \%$ of the population

G. There is no medical cure for either condition

H. IBS and IBD sufferers put an ongoing strain on NHS resources

I. Every aspect of a patient's life is affected by IBS or IBD symptoms which are highly embarrassing, unpredictable and painful 
J. These patients had been diagnosed between 1.5 and 10 years earlier

K. 100 IBS patients and 100 IBD patients were recruited

L. Each patient received five weekly healing sessions in addition to their conventional care

M. Healing sessions were provided by members of The Healing Trust to ensure uniformity of method and professional standards

N. The IBS and IBD groups were each split 50/50. One half began healing sessions immediately (Intervention Group). The other half waited for 12 weeks (Waiting List Group) before starting sessions so that comparisons could be made during this period.

0. Each patient completed three different questionnaires at Week $0,6,12$ and 24 to identify and measure changes.

P. MYMOP quality of life questionnaire: Whether using score improvements, 'effect size' or statistics, the results were clinically significant for both IBS and IBD groups equally, at Weeks 6, 12 and 24. Lives were significantly improved and effects were long-lasting

Q. Disease-specific quality of life questionnaires : results were in keeping with MYMOP

R. Disease-specific symptoms questionnaires:

a. IBS improvements were clinically determinable.

b. The IBD group comprised ulcerative colitis and Crohn's Disease. The ulcerative colitis group gained improvements but not significantly. Both Crohn's groups outstripped the score associated with remission but the size of the group was too small (24 participants) to draw conclusions.

S. In general, gains were retained for 19 weeks after the final healing session. Benefits may have lasted longer but this was the extent of our study

T. The results of the different questionnaires generally tallied with each other, thereby further confirming the validity of them all

U. There was little or no change in score for the Waiting List Groups immediately prior to starting their healing sessions at Week 12, despite continuing with their usual conventional care

V. After receiving healing sessions, the Waiting List Groups followed a similar pattern to the Intervention Groups, thereby reconfirming results

W. People who received all five sessions benefited more than those who had fewer

X. The benefits gained exceeded that which could be associated with placebo

Y. There were no side effects
Z. For the qualitative study, 22 of the participants were interviewed

a. Patients were highly sceptical that healing could help them

b. Comments supported the findings of the quantitative paper regarding improvements in quality of life and symptoms

c. Patients enjoyed the experience

d. Patients felt less anxious, more confident and more able to cope

Subsequent discussions with patients revealed that they were not willing to have healing outside of the NHS. The primary goal of the research trial was to see if healing improved lives, and the main tool chosen to measure this was the MYMOP questionnaire. MYMOP is centred around the patient's experience of life, not whether they have recovered from specific ailments. It aims to discover what is troubling a patient the most, and determine whether the treatment under investigation is bringing about improvements. Patients are asked to describe their two worst symptoms and then identify activities that are hindered by them. Patients give a score for each symptom and for each activity so that any changes can be measured. In our trial, we might expect bowel problems to be identified as the worst problem, but it could be something else entirely.

The group that received healing from the outset-the intervention group-gained a significant improvement for each of their two worst symptoms and also for activities at Week 6 (all at either $\mathrm{p}<0.001$ or $\mathrm{p}=0.001$ ). These significant gains were maintained to Week 12 (all at either $\mathrm{p}<0.001$ or $\mathrm{p}=0.001$ ) and to Week 24 (all at $\mathrm{p}<0.001$ or $\mathrm{p}=0.001$ ). The waiting list group had to wait 12 weeks before receiving healing so that comparisons could be made between those who received healing and those who did not. Once the waiting list people had received their healing sessions, they followed a similar pattern of improvement to the intervention group.

These excellent MYMOP results demonstrate that the research trial achieved its primary goal. It had established that adding healing sessions to conventional treatment improves the lives of patients with IBS and also the lives of patients with IBD.

MYMOP Scores; IBS and IBD

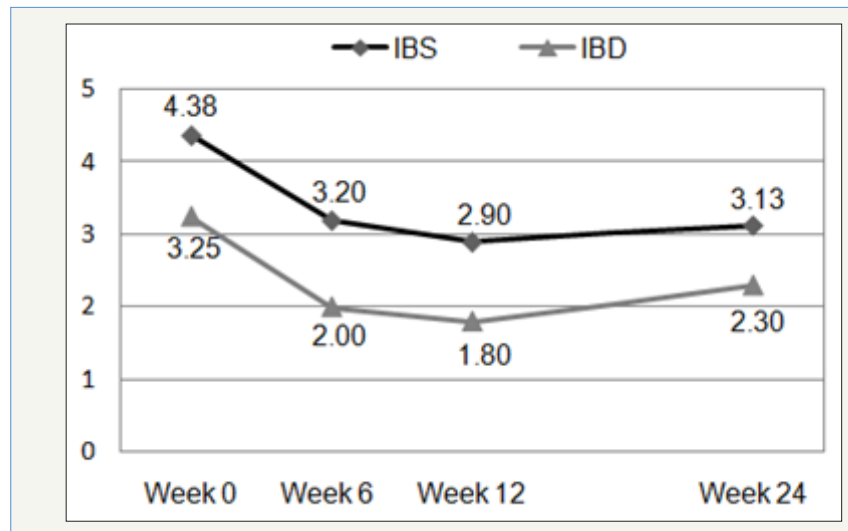

Figure 1 
A one-point reduction in score denotes a clinically noticeable improvement. These figures include 'Wellbeing' scores; if the graph included only 'Symptoms' and 'Activities' it would reveal more dramatic improvements than are indicated here (Figure 1).

The following research papers have been published in medical journals:

A. Main, quantitative paper:

http://www.sciencedirect.com/science/article/pii/ S187638201630422X

B. Secondary, qualitative paper:

https://bmccomplementalternmed.biomedcentral.com/ articles/10.1186/s12906-015-0611-x

But not many people read research papers, so I have felt driven to write an easy-read book about it:

Healing in a Hospital; Scientific Evidence that Spiritual Healing Improves Health ISBN 978-0-9575169-0-8 Available from Amazon.

My additional interpretations of the research data explain why the results are actually more impressive than conveyed in the research papers. With 200 citations, my book signposts a wealth of other research demonstrating that healing is beneficial for all kinds of conditions affecting the mind, body and/or emotions. This includes trials involving animals and plants, which dispel the myth that healing is only placebo.

Together, the compelling results demonstrate that healing has the potential to benefit anyone whether they are in pain, sick, stressed or depressed. Case studies add to the evidence. The findings of our research trial suggest that substantial cost savings could be made by the NHS, the Government and by businesses through adding healing to mainstream healthcare. 'Spectacular research results and a very impressive book. Patients and clinicians should take this seriously'. Dr Michael Dixon LVO, OBE, FRCGP, FRCC; Chair of Council, College of Medicine; Chair of NHS Alliance. 'An excellent and important book. Sandy Edwards' research is a major step toward a wider appreciation of this subject.' Larry Dossey MD, Author of One Mind; How Our Individual Mind Is Part of a Greater Consciousness and Why It Matters. Executive editor of Explore: The Journal of Science and Healing. 'Truly remarkable findings presented in an easy-read style. Stimulating and engrossing.' The Duchess of Rutland, Patron of NFSH/The Healing Trust.
Creative Commons Attribution 4.0 International License

For possible submissions Click Here
Submit Article

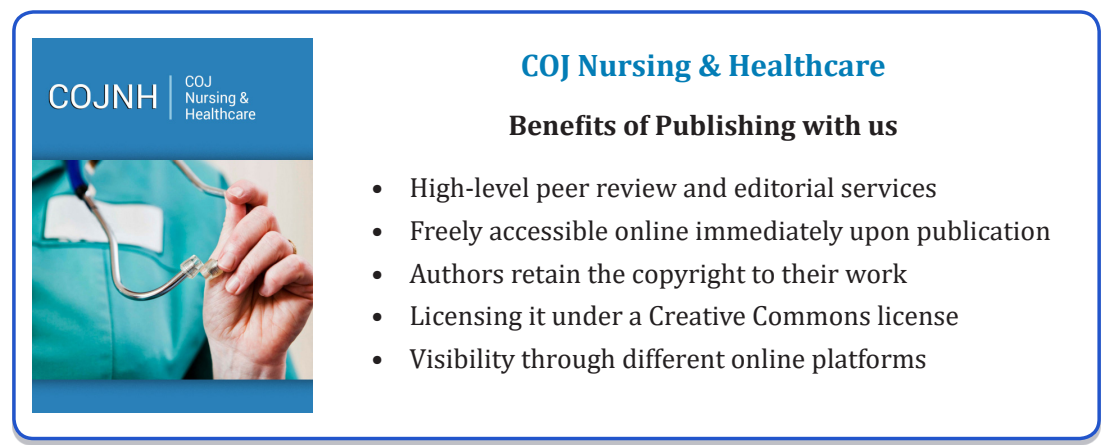

